\title{
Dynamic Capabilities and Their Relations with Elements of Digital Transformation in Portugal
}

\author{
Cláudio Márcio Campos de Mendonça ${ }^{1 *}$, António Manuel Valente de Andrade ${ }^{2}$ \\ ${ }^{1}$ Curso de Administração, Universidade Federal do Amapá, Amapá, BRAZIL \\ ${ }^{2}$ Centro de Estudos de Gestão e Economia, Católica Porto Business School, Porto, PORTUGAL
}

*Corresponding Author: cmarcio@gmail.com

Citation: Mendonça, C. M. C. and Andrade, A. M. V. (2018). Dynamic Capabilities and Their Relations with Elements of Digital Transformation in Portugal. Journal of Information Systems Engineering \& Management, 3(3), 23. https://doi.org/10.20897/jisem/2660

Published: July 16, 2018

\begin{abstract}
The objective of the article was to identify as relations between IoT, Big Data and Artificial Intelligence with the microfoundations of the dynamic capabilities. It was characterized as an exploratory, descriptive and inferential research, with a quantitative approach. In non-parametric tests (Chi-square / Spearman correlation), in Portuguese companies, totaling 137 respondents with valid questionnaires (only business and IT managers) were applied. It has been shown that as 3 technologies, Io'T, Big Data and IA, in different proportions of performance, are large in the 3 microfoundations of our dynamic capabilities. The highlight was for the performance presented by Big Data in the Seising microfoundation. The highest correlations were observed for the Seising microfoundation, with emphasis on the strong correlation between IoT and Big Data and moderate correlations between Big Data and AI.
\end{abstract}

Keywords: dynamic capabilities, internet of things, big data, artificial intelligence

\section{INTRODUCTION}

In recent years the economy has been evolving at high speed through a process of transformation, where the driving matrix is basically formed by advanced innovations in the areas: digital, material and biological. In the digital category of the fourth industrial revolution, there is an emphasis in cloud computing, IoT, Artificial Intelligence and Big Data, which are part of the so-called Digital Transformation, which is a perspective of the use of information and communication technology (ICT) where it comes to act as a preponderant element in the transformation and reconfiguration of organizational elements, such as: strategy, processes, culture and structures (Hess et al., 2016).

The digital transformation in Portugal, is undergoing the process of migration of the so-called take off zone, where the digitalization is relatively low, but with fast growth, to the Stand Out area, where those at that level have a high degree of digital development and increased productivity through technological innovations (Chakravorti et al., 2017).

In addition to this digital transformation, organizations need to be able to reconfigure themselves in the face of such a competitive market. These Dynamic Capabilities (DC) are being analysed as an event in organizations and arousing interest in the academic environment, as well as in the corporate environment and in its various segments. This article aims to identify the relationships between elements of digital transformation and the microfoundations of dynamic capacities. 


\section{THEORETICAL REFERENCE}

\section{Elements of Digital Transformation: IoT, Artificial Intelligence and Big Data}

As cloud computing (CC) is combined with technologies such as embedded systems, microelectronics, communication and sensors, the concept of "Internet das Coisas" from the English Internet of Things (IoT) arises. This term was first used by Ashton (2009) when working with RFID (Radio Frequency Identification) concept. However, today's definition is broader, as it encompasses a range of applications such as health services, public services, transportation, etc Gubbi et al. (2013). In addition, it is considered the new technological and economic wave (Mukherjee et al., 2017).

For Makridakis (2017) the impact of industrial and digital or information revolutions has substantially affected society, but there is a new revolution being formed by Artificial Intelligence (AI) and that will generate a strong impact on companies and jobs. Today's AI is present in everyday life for people and businesses. An example of which are voice recognition features, face recognition, and writing suggestions available on today's smartphones.

According to Schwab (2016) artificial intelligence and robotics, will generate a turnaround in organizations with respect to the administrative functions in which it will occupy. The author also states that by 2025 there will be an inflection point where $30 \%$ of the corporate audits will be performed by AI robots, and this will happen because AI finds it easy to match standards and automate processes, which makes the adoption of this technology be recommended.

On the other hand, Big Data is emerging as a relevant topic among scholars and professionals, and it is defined as a holistic approach to managing, processing and analysing data in five dimensions, and which aims to deliver sustained value, measure performance, create skills and improve the decision-making process. The big data makes it possible to improve the efficiency and effectiveness of organizations, and it allows the process of decision making to be based on evidence and not intuition (McAfee and Brynjolfsson, 2012).

The Big Data dimensions are called "5Vs", and they are: Volume - satisfaction, accessibility to data; Variety diversity of sources and types of data; Speed - time needed to access the information and to make a decision; Veracity - confidence in the accuracy presented by the data; and Value - what information improves on results, the financial value used to obtain data with a good level of quality (Maçada and Canary, 2014; McAfee and Brynjolfsson, 2012).

\section{Dynamic Capabilities}

The theme of Dynamic Capabilities (DC) has been seen as an event in organizations and arousing interest in the academic environment, as well as in the corporate environment in its most diverse segments, ranging from the strategic area to human resources management, marketing, innovation, entrepreneurship and information and knowledge management.

For Fernandes et al. (2017) and Vogel and Güttel (2013) DC currently emerges as a vibrant field of study within the theoretical framework based on the management of resources and strategies, and for authors there is a significant growth in the number of citations and articles that address the theme "Dynamic Capabilities". The origin of the DC, which is resource-based view (RBV) (Alvarenga et al., 2016; Teece, 2007; Wamba et al., 2017). From the point of view of dynamic capacities acting as routines and processes, Teece (2007) defends the necessity of micro-fundamentals of dynamic capacities that are related to processes, and that can: act by analysing the external environment in which the firm is inserted (Sensing) through processes which aim to: direct internal P\&D work; seek suppliers to complement the organization's innovations; seek scientific and technological developments outside the firm; recognize target market segments, changing customer needs and generating customer-driven innovations; take advantage of the chances/opportunities detected (seizing) in processes such as: customer solutions; selection of organizational boundaries; selection of decision-making protocols; build loyalty of commitment; decentralization and decomposition; and managing threats and transformations arisen from organizational changes (managing threats/transforming) with processes of: co-specialization; governance; and knowledge management.

In short, the dynamic capacity is the grouping of organizational skills, behaviours and organizational capacities, as well as processes and routines that lead the company to differentiate itself in the competitive market in face of its competitors. And, as it is stated by Teece (2007), although the long-term performance of the firm is determined in some way by the way the (external) business environment rewards its assets, the development and exercise of dynamic (internal) capabilities are at the centre of the business success or its failure. 


\section{METHODOLOGY}

The present study was characterized as exploratory, descriptive and inferential, because it tried to identify possible relations and differences between a set of variables, and without necessarily worrying about the issue of causality. They were analysed using non-parametric tests. Regarding the nature of the research and approach to the problem, a quantitative study was done, using the descriptive research survey method, with cross-section.

For the quantitative study the sampling used was non-probabilistic and its elements were selected according to the convenience of the researcher. For the application of the questionnaires an electronic instrument of questionnaires was used. The link was sent by e-mail, in an Institutional way, by the Universidade Católica do Porto, through its Newsletter, to the members of the Association of Former Students of the Faculty of Economics and Management of the Católica Porto Business School. A total of 247 questionnaires were answered. After the analysis and exclusion of incompletely answered questionnaires and the questionnaires answered by people who were not business or IT managers, there were still 137 valid questionnaires. The study used an adaptation of the importance matrix x performance of Martilla and James (1977), and in part of the model was added a dimension called "future importance" up to 2025 in the respondents' perception, since the elements of digital transformation, as stated by Kane et al. (2015), are still in the stage of maturation in organizations and this third dimension will bring the perspective of the importance of these technologies on the dynamic capacities in the next 7 years, that is, until 2025, the year when, according to Schwab (2016), some points of inflection of the fourth industrial revolution will be detected,.

One of the inferential tests developed was Qui-square independence, which aims to compare proportions, allowing it to assess the adherence between a frequency distribution associated with a sample consisting of observations expressed in any scale and a theoretical distribution (Guimarães and Cabral, 1997). Another nonparametric test used to analyse the correlations was the Spearman coefficient that evaluates the magnitude of the relationship between ordinal variables.

The Cronbach alpha obtained was relatively high for the questions involving the dynamic capacities, being 0.92 for the 9 questions of the 3 technologies, totalling 27 items with Likert-type scale. When separated by categories (technologies), the value of 0.909 was obtained for questions related to IoT, 0.919 for Big Data and 0.934 for Artificial Intelligence.

\section{ANALYSIS AND INTERPRETATION OF RESULTS}

\section{Respondents Profile}

In the descriptive statistics, there was a greater participation of respondents from large companies (49.6\%), which added to the percentage from medium-sized companies (16.1\%), they are the majority of respondents with $65.7 \%$. Micro-enterprises accounted for only $20.4 \%$, and small companies with the lowest percentage of $13.9 \%$. Of these companies, $59.1 \%$ are multinational and $40.9 \%$ are national, so most respondents are part of a company that operates in other countries. The researchers chose to select only questionnaires answered by managers, be they business or IT, and the results showed a broad predominance of business managers with $92.7 \%$, while IT managers were only $7.3 \%$.

\section{Descriptive Statistics of the Matrix Importance (current and future) x Performance}

According to Teece (2007) the dynamic capacity Sensing, which has processes that enables analysing of the internal and external environment in which the organization is inserted, and through the analysis of the means and medians obtained through Likert-type scale analysis, which among the 3 tecnhologies (IoT, Big Data and AI), Big Data has the best performance (median 4 and average 3.97), followed by IoT (median 4.00 and average 3.50), and lastly the use of Artificial Intelligence, still with an incipient performance or almost without use (median 2.00 and average 2.15). According to Dobre and Xhafa (2014), the technologies that involve Big Data are more accessible to organizations, which may be contributing to better performance among the 3 technologies surveyed. In addition, Big Data favours the capture of external data and information, which is the main focus of the dynamic capacity Sensing. An example is what occurs with social networks where very economical analyses are possible and opinions of the external environment are faster (Venkatram and Geetha, 2017). This task involves monitoring internal and external technological developments and assessing customer needs, expressed and latent, as well as: learning, interpretation and creative activity (Dobre and Xhafa, 2014). Such detection (sensing) is essential for the company to sustain itself over the long term as customers, competitors and technologies change (Teece et al., 2016).

The processes focused on customer solutions, selection of organizational boundaries, selection of decisionmaking protocols and related to the building of employee loyalty and commitment are part of the Seizing microfoundation of dynamic capabilities that allow the use of resources to meet needs and opportunities taking 


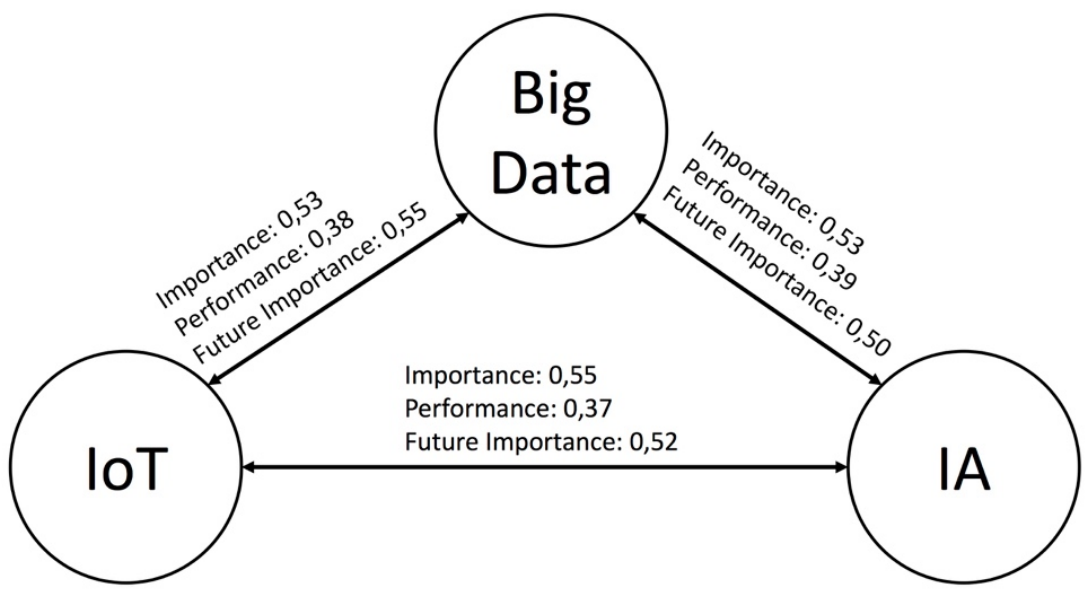

Figure 1. Spearman correlation between IoT, Big Data and AI and Sensing dynamic capacity

advantage of them (Teece, 2007; Teece et al., 2016). Higher averages and medians were identified in the three technologies if compared to the dynamic sensing and threat management capacities, with respect to performance. Once again there is a predominance in the performance of Big Data technology in relation to IoT and AI, with averages 4.41, 4.10 and 3.18, respectively. These averages, as well as the observed medians, that are superior in the performance of the 3 technologies for the capabilities of exploiting opportunities detected in the internal and external environment of the organization, suggest the greater use of technologies for these processes, and this is in agreement with what Teece (2007) says, who informs that to address the opportunities (Seizing), there must be maintenance and enhancement of technological competencies and complementary resources, and then when the opportunity is mature, investing heavily in the technologies and designs most likely to achieve a market acceptance.

For the dynamic capacity to seize opportunities, it was observed that the performance and importance (current and future) of the use of Big Data was superior to the other dynamic capacities and technologies. This fact may be occurring because this dynamic capacity has relation with the process of decision making, through the definition and use of decision protocols. The justification for using Big Data technology is due to its use on the process of decision making, where better decisions are sought, in order to increase the likelihood of success and risk minimization (Erevelles et al., 2016; Venkatram and Geetha, 2017; Vieira et al., 2017).

According to Meirelles and Camargo (2014) and Teece (2007) there is a third capacity that serves as a foundation for dynamic capacities, which is called the capacity to manage threats and transformations (Managing Threats/Transforming). It was observed through the analysis of averages and medians, that the performance of Big Data technology was superior to IoT and AI. The superior performance of Big Data technology in this microfoundation can favour the learning process of the organization, and according to Barrales-Molina et al. (2013), there is significant influence and effect of the learning mechanisms in generating dynamic capacities.

\section{Inferential Statistics (Chi-square and Spearman's Correlation) of the Elements of Digital Transformation and Microfoundations of Dynamic Capabilities}

Based on the non-parametric tests the data was analysed from two perspectives: from the point of view of the correlations between the technologies in the face of each micro-foundation of the dynamic capacities; and from the perspective of the correlations between importance $\mathrm{x}$ performance $\mathrm{x}$ perspective of future importance in the 3 technologies. Initially the chi-square test was performed, where the hypothesis $\mathrm{H}_{0}$, meant that there was no statistically significant association, and $\mathrm{H}_{1}$ meant that there was association. The results show that the associations are statistically significant among all technologies and micro-foundations of dynamic capacities. After obtaining the Chi-square results, we applied the Sperman correlation test on the correlations involving IoT, Big Data and AI, with the dynamic capabilities in the 3 micro-foundations Teece (2007), in order to analyse the strength of the correlations.

In the Sensing dynamic capacity, which has processes that enables the analysis of the internal and external environment, we observed weak correlations regarding the performance observed by the respondents, among the 3 technologies. These relatively low correlations of performance may be due to the currently low use of these technologies, for this micro-foundation specifically, as demonstrated in the descriptive statistics.

Regarding the current importance attributed, moderate correlations between the three technologies were detected. The highest being the correlations between IoT and AI technologies. When analysing the correlation involving the perceived future importance, the moderate correlation observed was between IoT and Big Data technologies, as shown in Figure 1. 


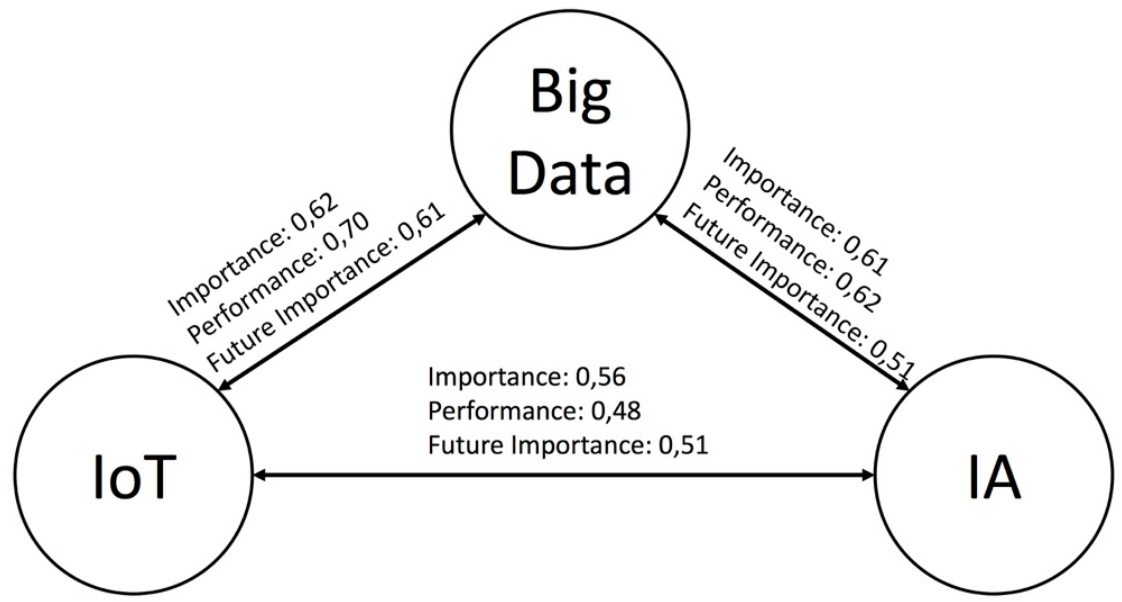

Figure 2. Spearman correlation between IoT, Big Data and AI and the dynamic Seizing ability

It is worth emphasizing the greater correlation between IoT and Big Data in the current and future importance for this micro-foundation which is related to the processes that enable the analysis of environments in search of innovation and also taking into consideration external aspects to the organizational environment. It is suggested that this higher correlation may be happening because of the managers' perception that IoT allows people and things to connect at anytime, anywhere through devices that can transmit data with anything on any network. This transmitted data together with relevant information which are converted into knowledge and can be used by technologies such as Big Data, for Yerpude and Singhal (2017). This may reveal many emerging research orientations in some very specific and specialized domains.

When analysing the correlations between technologies, with the micro-foundation of the dynamic Seizing capability (taking advantage of chances and opportunities), which involves processes focused on customer solutions, selection of organizational boundaries, decision-making processes, and loyalty and commitment, it was observed, as shown in Figure 2, that there is a predominance in moderate correlations for the current importance (0.62) and the perspective of future importance (0.61), and strong correlation for performance (0.70) between IoT and Big Data technologies. This strong correlation can also be related to the real use of IoT and Big Data technologies in the Portuguese companies surveyed, as it was also demonstrated in the descriptive statistics, obtaining higher values for this micro-foundation of exploring the detected opportunities.

These higher correlations between Io'T and Big Data may be occurring, as stated by Yerpude and Singhal (2017), since IoT is evolving and its junction with Big Data enables correct decision making at the right moments, as well as allowing the identification of hidden trends and allow for future forecasting. Emphasis is also placed on the important role played by Io'Ts in operational agility, indicating the need for managers to invest in such destructive technologies and to improve the IT organizational infrastructure of their enterprises, in order to take advantage of a large amount of data and information through devices connected to the Internet to develop operational agility and manufacturing scalability (Akhtar et al., 2017).

Because it was in the micro-foundation where the best performance of the three technologies was obtained, also observed was the existence of moderate correlations between Big Data and AI technologies. This may suggest that organizations have already begun to understand the relationship between Big Data and AI techniques. For Akhtar et al. (2017), today's business operations are flooded with structured and unstructured data, and modern companies can rely on new tools and techniques to process data and share information, and expert systems of artificial intelligence can provide their data mining tools and learning tools of machines for the conversion of information into knowledge (Gubbi et al., 2013; Pan, 2016).

Regarding the dynamic ability to manage threats and transformations arisen from organizational changes (managing threats/transforming), with processes linked to decentralization and decomposition, co-specialization, governance and knowledge management, we can see a prominence, as shown in Figure 3, for the moderate correlations between Big Data and AI technologies, where the observed performance was 0.60 , the current importance attributed was 0.67 and the future perspective of importance was 0.66 .

What can justify these higher correlations between Big Data and AI for this micro-foundation of the dynamic capacity is that there is a perception, also taking into account descriptive statistics, with a mean and median (4.09 and 4.0 respectively) that are high for Big Data performance for this micro-foundation, which has a relation, as Meirelles and Camargo (2014) states, that they combine assets, have processes that integrate external know-how, learning, sharing and knowledge integration. These characteristics demand a treatment of information and knowledge, which according to Pan (2016), is possible with the integration between Big Data and AI that enables the use of important data and transform them into usable knowledge, and from knowledge to intelligent behaviour, 


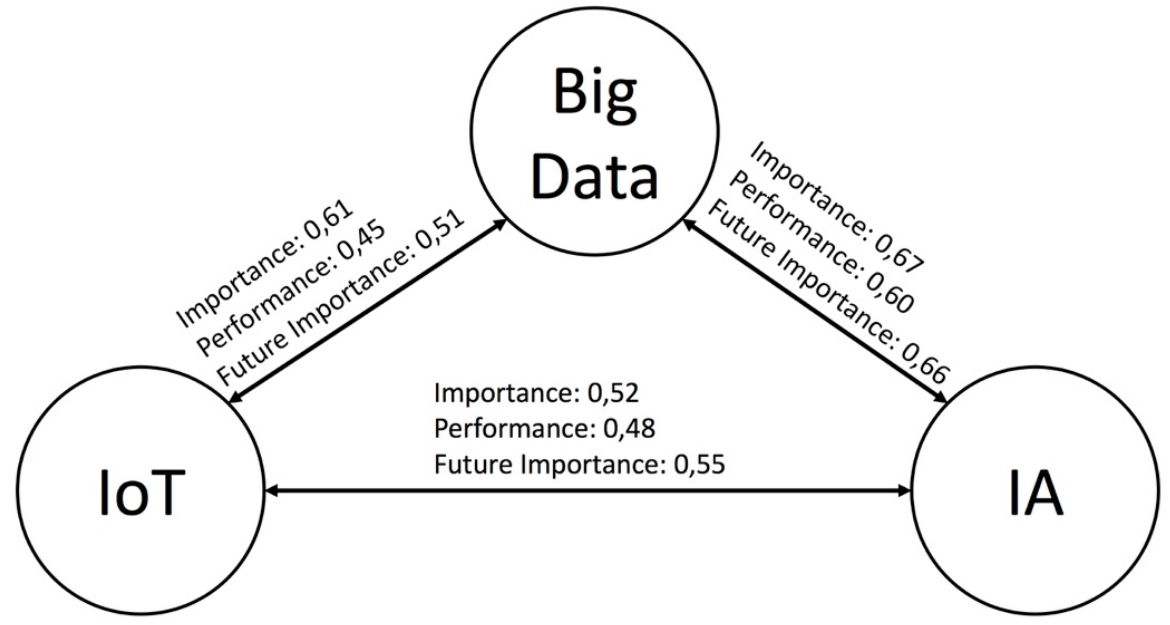

Figure 3. Spearman correlation between IoT, Big Data and AI and the dynamic capacity Managing Threats/Transforming

connects data from multiple fields and supports merger and innovative services across different areas to develop new technologies and operations.

When evaluating the correlations between the current importance vs. current performance and the perspective of future importance vs. current performance of the 3 technologies and their respective micro-foundations of dynamic capacities, we could see larger (moderate) correlations in the micro-foundation of seizing opportunities (Seizing) and between the current importance vs. current performance. This data suggests, when we also analyse the averages and the medians that this may have happened due to the better performance of these 3 technologies for this micro-foundation of dynamic capacity. It was also possible to observe an increase in the future importance compared to the current importance in the 3 technologies for the 3 micro-foundations, mainly the Artificial Intelligence technology.

\section{FINAL CONSIDERATIONS}

The results were presented using descriptive and inferential statistics (Chi-square test and Spearman's correlation), and it was demonstrated that the three technologies, IoT, Big Data and AI, in different proportions of performance, are used in the 3 micro-foundations (to analyse the environment; to seize opportunities; to manage threats and transformations) of dynamic capabilities. The highlight was for the performance presented by Big Data, which obtained the highest values in the 3 micro-foundations. On the other hand, artificial intelligence, in terms of performance, is a more distant reality of Portuguese companies, obtaining the lowest values, and IoT was somewhere in between as far as performance is concerned. For the 3 technologies, the highest values are related to the Seizing micro-foundation (seize the opportunities) which is related to processes that involve solutions for clients, decision making, definition of organizational boundaries, as well as loyalty and commitment of the employees. Therefore, it is suggested that the best performance is the one of the Big Data technology in the microfoundation Seizing. This may be due to increased access to these technologies, even by legacy transactional systems such as ERP, and Datawarehouse frameworks and Analytics solutions that are in some way related to Big Data technology.

With respect to the current importance and prospect of future importance up to 2025, for these 3 technologies in the micro-foundations, Big Data technology was again observed with greater prominence, followed by IoT and AI. It is worth emphasizing that analysing the existing gaps between current importance and future importance, the technology that has a greater difference is Artificial Intelligence in the 3 micro-foundations. It is suggested that, even with the low use (evaluated in the performance), the managers believe that AI will have increased importance in the organizations within the next 7 years, mainly in the micro-foundations Seizing and Sensing, respectively. Given the analysis of the correlations between the 3 technologies and the 3 micro-foundations, it was possible to infer from the non-parametric tests, that there are statistically significant associations between them and for the Sensing micro-foundation we found weak correlations related to performance and the 3 technologies. This may be happening due to the low use for this micro-foundation, which has processes related to finding suppliers to complement innovations, searching for scientific and technological developments external to the organization, and seeking recognition of customer segments external to the organization.

The higher correlations were observed for the Seizing micro-fund (taking advantage of the chances and opportunities detected), with emphasis on the strong correlation of performance between IoT and Big Data 
technologies, which may be occurring due to the greater use of the two technologies. Moderate correlations were also observed between Big Data and AI, even with the low performance of Artificial Intelligence technology. These correlations may be associated with the types of processes that involve this micro-foundation of dynamic capacity, since they include seeking solutions for clients and decision making. These types of processes need to analyse large quantities of data of companies. Perhaps for this reason Big Data is highlighted and with moderate and strong correlations with other technologies.

On the other hand, the micro-foundation of the dynamic capacity to manage threats and transformations due to organizational changes has a greater (moderate) correlation between Big Data and AI technologies, which may be occurring due to the processes of this micro-foundation being related to the combination of assets, knowledge integration (internal and external), learning and knowledge integration, which are characteristics conducive to the integration of these two technologies that allow knowledge mining and data combination with other technologies in order to promote new methods and a dynamic evolution. When comparing the correlations between current importance versus current performance and perspective of future importance versus current performance, the moderate correlation between the current importance versus performance, shows that the performance/use of the technology may be influencing this perception of importance, the higher the performance, the greater the importance attributed to technology, especially to the micro-foundation Seizing (Seizing opportunities).

\section{ACKNOWLEDGMENTS}

This work is financed by National Funds of FCT - Foundation for Science and Technology within the scope of the project UID/GES/00731/2016.

\section{REFERENCES}

Akhtar, P., Khan, Z., Tarba, S. and Jayawickrama, U. (2017). The Internet of Things, dynamic data and information processing capabilities, and operational agility. Technological Forecasting and Social Change, (October 2016), 0-1. https://doi.org/10.1016/j.techfore.2017.04.023

Alvarenga, M. A., Leite, N. R. P., Freitas, A. D. G. de and Ruas, R. L. (2016). Capacidades dinâmicas e vantagem competitiva em ambientes de mudanças constantes, à luz da análise do filme 'Recém-chegada'. REGE - Revista de Gestão, 24, 35-44. https://doi.org/10.1016/j.rege.2016.06.010

Ashton, K. (2009). That "Internet of Things" Thing. RFiD Journal, 4986. https:/ / doi.org/10.1145/2967977

Barrales-Molina, V., Bustinza, Ó. F. and Gutiérrez-Gutiérrez, L. J. (2013). Explaining the Causes and Effects of Dynamic Capabilities Generation: A Multiple-Indicator Multiple-Cause Modelling Approach. British Journal of Management, 24(4), 571-591. https:// doi.org/10.1111/j.1467-8551.2012.00829.x

Chakravorti, B., Bhalla, A. and Chaturvedi, R. S. (2017). 60 Countries' Digital Competitiveness, Indexed. Harvard Business Review, 1-10.

Dobre, C. and Xhafa, F. (2014). Intelligent services for Big data science. Future Generation Computer Systems, 37, $267-$ 281. https://doi.org/10.1016/j.future.2013.07.014

Erevelles, S., Fukawa, N. and Swayne, L. (2016). Big Data consumer analytics and the transformation of marketing. Journal of Business Research, 69(2), 897-904. https://doi.org/10.1016/j.jbusres.2015.07.001

Fernandes, C., Ferreira, J. J., Raposo, M. L., Estevão, C., Peris-Ortiz, M. and Rueda-Armengot, C. (2017). The dynamic capabilities perspective of strategic management: a co-citation analysis. Scientometrics, 529-555. https://doi.org/10.1007/s11192-017-2397-8

Gubbi, J., Buyya, R., Marusic, S. and Palaniswami, M. (2013). Internet of Things (IoT): A vision, architectural elements, and future directions. Future Generation Computer Systems, 29(7), 1645-1660. https://doi.org/10.1016/j.future.2013.01.010

Guimarães, R. C. and Cabral, J. A. S. (1997). Estatística (Edição Rev). Porto: McGraw-Hill de Portugal.

Hess, T., Benlian, A., Matt, C. and Wiesböck, F. (2016). Options for Formulating a Digital Transformation Strategy. MIS Quarterly Executive, 15(2), 123-139.

Kane, G. C., Palmer, D., Philips Nguyen, A., Kiron, D. and Buckley, N. (2015). Strategy, Not Technology, Drives Digital Transformation. MIT Sloan Management Review, (57181), 27. Available at: https://doi.org/http://www2.deloitte.com/content/dam/Deloitte/cn/Documents/technology-mediatelecommunications/deloitte-cn-tmt-strategy-not-technology-drive-digital-transformation-en-150930.pdf

Maçada, A. C. G. and Canary, V. P. (2014). A Tomada de Decisão no Contexto do Big Data: estudo de caso único. XXXVIII Encontro da ANPAD - EnANPAD, XXXVIII, 1-17.

Makridakis, S. (2017). The Forthcoming Artificial Intelligence (AI) Revolution: Its Impact on Society and Firms, 90, 46-60. https:// doi.org/10.1016/j.futures.2017.03.006 
Martilla, J. A. and James, J. C. (1977). Importance-Performance Analysis. Journal of Marketing, 41(1), 77. https://doi.org/10.2307/1250495

McAfee, A. and Brynjolfsson, E. (2012). Big Data : The Management Revolution. Har, (OctOBeR).

Meirelles, D. S. e and Camargo, Á. A. B. (2014). Capacidades Dinâmicas: O Que São e Como Identificá-las? Dynamic Capabilities: What Are They and How to Identify Them? Revista de Administração Contemporânea, 18(Dezembro), 41-64. https://doi.org/10.1590/1982-7849rac20141289

Mukherjee, M., Adhikary, I., Mondal, S., Mondal, A. K., Pundir, M. and Chowdary, V. (2017). A vision of IoT: Applications, challenges, and opportunities with China perspective. Advances in Intelligent Systems and Computing, 479(4), 553-559. https://doi.org/10.1007/978-981-10-1708-7_63

Pan, Y. (2016). Heading toward Artificial Intelligence 2.0. Engineering, 2(4), 409-413. https://doi.org/10.1016/J.ENG.2016.04.018

Schwab, K. (2016). A Quarta Revolução Industrial (Edipro). São Paulo. Available at: http://www.edipro.com.br/produto/a-quarta-revolucao-industrial/

Teece, D. J. (2007). Explicating Dynamic Capabilities: The Nature and Microfoundations of (Sustainable) Enterprise Performance. Strategic Management Journal, 1319-1350. https://doi.org/10.1002/smj.640

Teece, D., Peteraf, M. and Leih, S. (2016). Dynamic Capabilities and Organizational Agility: Risk, Uncertainty, and Strategy in the Innovation Economy. California Management review, 58(4). https://doi.org/10.1525/cmr.2016.58.4.13

Venkatram, K. and Geetha, M. A. (2017). Review on Big Data Analytics - Concepts, Philosophy, Process and Applications. Cybernetics and Information Technologies, 17(2), 3-27. https:// doi.org/10.1515/cait-2017-0013

Vieira, V., Pedrosa, I. and Soares, B. H. (2017). Big data analytics: An approach using audit experts' interviews. In 2017 12th Iberian Conference on Information Systems and Technologies (CISTI) (p. 1-6). IEEE. https://doi.org/10.23919/CISTI.2017.7976069

Vogel, R. and Güttel, W. H. (2013). The dynamic capability view in strategic management: A bibliometric review. International Journal of Management Reviews, 15(4). https:// doi.org/10.1111/ijmr.12000

Wamba, S. F., Gunasekaran, A., Akter, S., Ren, S. J., Dubey, R. and Childe, S. J. (2017). Big data analytics and firm performance: Effects of dynamic capabilities. Journal of Business Research, 70, 356-365. https://doi.org/10.1016/j.jbusres.2016.08.009

Yerpude, S. and Singhal, T. K. (2017). Internet of Things and its impact on Business Analytics. Indian Journal of Science and Technology, 10(5), 1-6. https://doi.org/10.17485/ijst/2017/v10i5/109348 